\title{
Surgery for autoimmune aortitis: unanswered questions
}

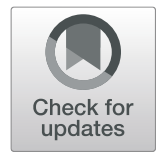

Amr A. Arafate

\begin{abstract}
Background: The aorta is rarely affected by autoimmune vasculitis, which can lead to aortic dilatation requiring surgery. Autoimmune aortitis may affect one aortic segment or the entire aorta, and in some cases, the aorta may be affected at different time intervals. Because of the rarity of the disease and the limited cases described in the literature, management of autoimmune aortitis is still controversial. We aimed to review the current literature evidence regarding these controversial aspects for the management of autoimmune aortitis and give recommendations based on this evidence.

Main text: Immunosuppressants are generally indicated in vasculitis to halt the progression of the disease; however, its role after the occurrence of aortic dilatation is debatable since further aortic dilatation would eventually occur because of the weakness of the arterial wall. In patients with a localized ascending aortic dilatation who required surgery, the optimal approach for the distal aorta is not known. If the probability of disease progression is high, it is not known whether the patients would benefit from postoperative immunosuppressants or further distal aortic intervention may be required. The risk of rupture of the weakened aortic wall was not established, and it is debatable at which diameter should these patients have surgery. In patients with previous ascending surgery for autoimmune aortitis, the endovascular management of the distal aortic disease has not been studied. The inflammatory process may extend to affect the aortic valve or the coronary vessels, which may require special attention during the procedure.

Conclusion: Patients with diagnosed autoimmune aortitis are prone to the development of the distal aortic disease, and endovascular intervention is feasible in those patients. Patients with concomitant aortic valve can be managed with the aortic valve-sparing procedure, and preoperative screening for coronary disease is recommended. Immunosuppressants should be used early before aortic dilatation, and its role postoperatively is controversial.
\end{abstract}

Keywords: Autoimmune aortitis, Giant cell aortitis, Takayasu aortitis, Non-infectious aortitis

\section{Background}

Autoimmune aortitis is a rare cause of aortic disease requiring surgery [1]. Several types of vasculitic disease can affect the aortic wall; however, the clinical features are non-specific, and the preoperative diagnosis is difficult, especially in patients with no extra-aortic disease $[1,2]$. There are several unresolved issues related to autoimmune aortitis that can affect the surgical decision and patients' management. Autoimmune aortitis is classified based on the type of the vasculitis, and there are no anatomical or surgical classifications that can guide

\section{Correspondence: amr.arafat@med.tanta.edu.eg}

Cardiothoracic Surgery Department, Faculty of Medicine, Tanta University, Al-Geish Street, Tanta, Gharbyia 31529, Egypt patient management. Patients with autoimmune aortitis may have distal disease progression after surgical correction of the proximal disease, and the role of immunosuppressants to halt this progression is debatable. Optimal management of the distal aortic disease is not settled, and it is not known if these patients may benefit from prophylactic interventions at the time of proximal aortic repair or staged endovascular repair could be warranted.

The European Society of Cardiology (ESC) guidelines for the management of aortic disease did not define a threshold at which surgery is recommended in patients with aneurysmal aortitis, and the risk of aortic rupture in these patients are not known compared to the 
atherosclerotic or connective tissue aneurysms [3]. The use of immunosuppressants modulates the course of the disease; however, its role after aortic dilatation and surgery is controversial. The probability of the involvement of the coronary arteries and the aortic valve with the inflammatory process is not established but may require special attention intraoperatively. We aimed to review the current literature evidence regarding these controversial aspects for the management of autoimmune aortitis and give recommendations based on this evidence.

\section{Classification of autoimmune aortitis}

Generally, vasculitis is classified according to the vessels and organs affected into large, medium, small, and variable vessels vasculitis, single organ vasculitis, vasculitis associated with systemic autoimmune disease [4], and vasculitis associated with probable etiology [5]. Despite being the largest artery, the aorta can be affected by all types of vasculitis. The aorta is mainly affected by large vessel vasculitis with its two variants giant cell and Takayasu arteritis [6]. Clinically, the American College of Rheumatology criteria are used to diagnose giant cell (GCA) and Takayasu arteritis $[7,8]$. Takayasu tends to occur in patients younger than 40 years and has more predilection to the subclavian artery $[5,7]$; on the other hand, GCA tends to affect patients above 50 years and affects more the carotid and vertebral arteries [5,8]. Although giant cell and Takayasu arteritis are considered two distinct disorders based on the clinical presentation, some authors considered them as one disease entity, and their clinical picture represents a spectrum within a single disorder [9].

The prevalence of autoimmune aortitis in surgically resected aortas varies between 1.8 and $8.8 \%$ [1, 2, 10, 11]. Histologically, both GCA and Takayasu are granulomatous diseases affecting all layers of the aortic wall, which becomes infiltrated with lymphocytes, macrophages, and multinucleated giant cells [5]. The classic Takayasu's aortitis is a pan-aortitis, more commonly associated with intimal and adventitial thickening with intraluminal stenosis [10]. In GCA, the aorta is thickened mainly due to the involvement of the media with the destruction of the elastic lamina associated with medial necrosis and the development of an aneurysm [10], and it is characterized by focal arteritis and skip lesions [12].

The isolated aortitis-also known as single organ vasculitis-is an increasingly recognized form of aortitis mostly diagnosed after surgical treatment of an aortic aneurysm. Isolated aortitis is localized inflammation of the aortic wall, not associated with systemic disease and does not fit the diagnostic criteria of GCA or Takayasu arteritis $[6,13,14]$.

Early diagnosed autoimmune aortitis requires immunosuppressant therapy. On the other hand, infectious aortitis requires antimicrobial therapy and surgical intervention. The diagnosis of autoimmune aortitis can be suspected from the associated clinical syndrome, and the American College of Rheumatology criteria $[7,8]$ can be used to diagnose GCA and Takayasu diseases. However, the preoperative diagnosis of the isolated variant presents a clinical challenge, especially in the absence of systemic symptoms. Several studies had attempted to identify the risk factors suspecting underlying inflammatory component of the aortic disease requiring surgery. Schmidt and associates found the incidence of aortitis was $6.1 \%$, and the predictors of idiopathic aortitis were a history of connective tissue disorders, diabetes mellitus, age more than 67 years, and aortic valve disease [15]. Other studies found that patients undergoing surgery for aortitis complications had associated hypertension [16-18], peripheral vascular disease [18], coronary artery disease [18], shortness of breath, and aortic incompetence [16-18]. From Cleveland Clinic experience, they found that aortitis occurred more frequently in females and the majority of the patients are hypertensive and smokers and had associated aortic valve disease. All age groups can be affected by autoimmune aortitis ranging from 20 to 87 years old $[1,13]$. Despite these trials to predict the inflammatory nature of the aneurysm, none of the risk factors are specific.

Imaging plays a vital role in diagnosing aortitis. Computed tomography and magnetic resonance imaging had replaced angiography as the modality of choice in aortitis [19]. Both of them show aortic wall thickening or thinning depending on the stage of the disease, vessel wall edema which could reflect disease activity, luminal narrowing, periaortic thickening, and wall ulceration, dissection or aneurysm formation [20]. MRI is superior to $\mathrm{CT}$ in demonstrating the vessel wall and the edema; however, CT can show wall calcification and disease progression. Despite the superiority of MRI in detecting vessel wall edema, the correlation of edema with disease activity is controversial. MRI showed a decrease in vessel wall edema in a patient with GCA after 2 weeks of steroid use [21]. However, in a previous study from Cleveland Clinic on 24 patients with Takayasu disease, there was no correlation between vessel wall edema shown on MRI and acute phase reactants [22]. Recently, FDG-PET CT was found to have a role in diagnosing aortitis, which shows an increase in FGD uptake in the aorta [23-25]. In our experience, the operative inspection may play an important role in the diagnosis of aortitis, and the glossy white intima with only some yellow streaks is considered the typical finding in GCA This glossy white look represents the change from the loss of elastic lamellae and smooth muscle cells and the formation of scar tissue rich in proteoglycans. All resected aortic tissue 
should be sent for histopathological examination to confirm the etiological diagnosis and identify the type of vasculitis [26].

Currently, there is no standard classification that can guide the decision of surgery. Svensson, Arafat, and their coworkers had classified the disease based on the possible etiological factor [1]. However, recognizing the disease preoperatively still presents an ongoing challenge and, in their series, more than half of their patients were diagnosed postoperatively. The diagnosis of autoimmune aortitis requires a high level of suspicious, female patients presented with ascending aortic dilatation with or without the distal disease, and elevated inflammatory markers should undergo further evaluation with MRI or PET scan.

\section{The threshold for intervention}

Autoimmune aortitis causes progressive thinning of the aortic wall, and the risk of rupture has not been evaluated before. In the series by Arafat and associates, 16\% of the patients had a surgical intervention because of acute aortic syndrome or chronic dissection in the ascending aorta [13]. Development of aortic dissection in patients with aortitis was attributed to the delayed use of steroid from the time of onset of symptoms to the diagnosis, and it was found that dissection is an early complication of GCA compared with other causes of the aneurysm [27]. There is not enough evidence in the literature supporting the intervention at specific diameter in autoimmune aortitis [28], but considering the high incidence of acute events reported in the scarce series, intervention at lower aortic diameters than the atherosclerotic aneurysms could be warranted.

\section{The distal aorta}

The preoperative diagnosis of vasculitis is essential to guide the management of the distal aorta. Disease progression was not evaluated in large and several series; however, the largest series up to date by Clifford and Arafat and their colleagues found that $29 \%$ of the patients required distal aortic intervention during an 8year follow-up and many patients developed other vascular lesions [13, 29]. Wang and associates found 7 of 15 patients with GCA who had ascending aortic surgery developed the distal aortic disease, and 5 required distal reinterventions in a mean time of 58 months. The risk of distal aortic disease was 11 -fold in comparison to the control group [30]. The progressive aortic dilatation was noted in all levels from the arch to the infrarenal aorta after ascending aortic surgery [31].

Despite the limited studies on autoimmune aortitis, the current evidence supports distal disease progression in patients with GCA and isolated aortitis [32]. Those patients may benefit from additional prophylactic interventions during their primary surgery, such as the deliberate use of elephant trunk procedure to manage those patients. Further studies are required to adequately describe the optimal surgical procedure for the management of these patients.

\section{Endovascular repair}

Patients who had ascending aortic surgery for autoimmune aortitis are prone to frequent reinterventions, mostly involving the distal aortic segments. Disease progression in the distal aorta and progressive dilatation of the weakened inflamed distal aortic wall observed in those patients raise the question about the feasibility of endovascular aortic repair (TEVAR). Currently, there is not enough evidence for the feasibility of stent grafting in these patients. A study had evaluated the results of endovascular stenting in patients with aortopathy including Marfan, GCA, and Takayasu aortitis [33], technical success was 91.7\%, endoleak occurred in $16.7 \%$, and no aneurysm-related mortality was reported. Recent reports had a good outcome of TEVAR in patients with the genetic aortic disease [34]; however, reinterventions are common.

In a study by Arafat and coworkers, reinterventions after TEVAR occurred in the distal segments because of continuous disease progression, and aortic growth, three interventions for endoleak were reported, and all reinterventions were managed endovascularly [13]. In the same study, none of the Takayasu patients who had ascending aortic repair for aortitis required later TEVAR; this may reflect the progression of the aortic pathology in Takayasu patients, which tends to be obstructive [1]. On the other hand, patients who had isolated aortitis required more reinterventions after TEVAR than patients with GCA and aortitis associated with systemic autoimmune disease $[1,13]$.

Aortic diameters at the level of the mid arch and the maximum descending aortic diameters were decreased post-stenting. Although the decrease in diameters was not statistically significant, the stent graft succeeded to stop the progressive aortic expansion in patients with aortitis $[1,13,29]$. Patients with active inflammation of the aortic wall may benefit from endovascular interventions since open repair is associated with the formation of pseudoaneurysm at the suture line $[35,36]$. The feasibility of endovascular interventions in inflammatory aortitis came from sporadic case reports [37, 38] and abdominal aortic aneurysm interventions [39]; however, the current evidence supports its feasibility. Additionally, several endovascular procedures are performed without a confirmatory aortic specimen to exclude vasculitis [40].

\section{The aortic valve}

Aortic valve pathology was a positive predictor of inflammatory origin of the aneurysm in several studies [16-18]. Concomitant aortic valve surgery was performed in 51\% 
and $80 \%$ of the patients $[13,31]$ who had ascending aortic surgery for autoimmune aortitis. The aortic valve can be affected as a part of the systemic disease as in Cogan's syndrome and Behcet disease [41] while aortic valve affection in Takayasu is rare. Long-term results of aortic valve repair and the durability of aortic bioprosthesis are not known in these patients. Mennandar and colleagues performed ascending aortic surgery in 100 patients with aortitis, 38 had an aortic valve-sparing procedure, 30 had aortic valve replacement, and 30 patients had competent valves. There was no difference in operative mortality and morbidity between groups. Postoperative echo was available in 59 patients with no significant difference between groups related to the valve and ventricular function. Two patients with prior aortic valve-sparing procedure had aortic valve replacement after 1 year, and one developed aortic regurge and treated conservatively. They concluded that the aortic valve-sparing procedure is technically feasible in patients with aortitis, but long-term results are unknown [42].

Aortic valve disease is associated with autoimmune ascending aortitis; however, the inflammatory nature of this association cannot be elicited, and reinterventions after aortic valve repair or aortic valve-sparing procedure is not common. This supports the feasibility of these procedures in patients with autoimmune aortitis.

\section{Concomitant coronary artery disease}

Autoimmune diseases causing aortitis are classified as large vessel vasculitis; however, they are not exclusive for large vessel disease. The blindness that can occur with GCA is attributed to small vessel affection of the ophthalmic vessels. Concomitant coronary artery bypass grafting (CABG) was reported in $25 \%$ of patients who had surgery for autoimmune aortitis [1, 13]. It is not clear whether the associated coronary lesions were atherosclerotic or vasculitis.

Several case reports described non-atherosclerotic coronary disease with or without associated aortitis [43, 44]. Many of these series reported the association of coronary artery disease with IgG4 disease [45] and used PET scan for screening [46]. The current guidelines do not address the management of coronary arteries in patients presenting for surgery for autoimmune aortitis. Many of those patients are young and asymptomatic, and screening for the coronary artery disease is not recommended. Based on the high association between aortitis and coronary artery disease in which the etiology of both lesions cannot be clearly separated, it is recommended to screen high-risk patients undergoing aortic surgery for the autoimmune cause for the presence of concomitant coronary artery disease. Patients with positive screening results can benefit from a PET scan to demonstrate the activity of the disease and assess the possibility of preoperative steroid therapy. There is no definitive recommendation on how to manage concomitant coronary lesions; however, a similar management plan to atherosclerotic coronary artery disease is recommended until we have enough evidence in literature towards alternate practice.

\section{Follow-up and immunosuppressants}

Current guidelines for the management of thoracic aortic disease recommend preoperative treatment with immunosuppressant drugs in patients with elevated inflammatory markers. However, there are no guidelines for postoperative management of these patients $[11,28]$. Rojo-Leyva and associates recommended postoperative treatment with immunosuppressants if there is evidence of disease progression beyond the resected segment [11].

The effect of postoperative immunosuppressant on the incidence of reintervention is not known. In a large series from Cleveland Clinic, postoperative immunosuppressant did not affect the reintervention rate [1]. Blumstein and fellows found that GCA patients treated with steroids had complete resolution of the inflammation on histological analysis compared to non-treated patients indicating that the disease is steroid responsive [47]. Rojo-Leyva and colleagues treated 11 patients with steroids after aortic surgery and had a mean follow-up of 35.5 months without the development of an aneurysm; however, 6 of 25 that were not treated with steroid had a mean follow-up of 41.2 months and developed subsequent aneurysms [11]. Miller and coworkers found 10\% of 21 patients with isolated aortitis developed aneurysms after surgical repair ( 2 treated with steroids) and $21 \%$ of 14 patients with GCA developed aneurysm even though 11 of them were on steroid ( $p$ value $=0.09)$ [10]. Wang and associates treated $3 / 15$ patients with postoperative steroids, one of them developed distal aortic disease [30]. The ineffectiveness of postoperative immunosuppressants therapy on the incidence of distal reintervention in our experience could be attributed to the late presentation of these patients to surgery especially with lack of signs and symptoms suggestive of inflammatory nature of their aneurysms. Early discovery of these patients and treatment with immunosuppressants before developing surgical aortic disease could reverse the pathological process and slow disease progression before medial destruction occurs.

\section{Conclusion and recommendations}

Autoimmune aortitis is an under-recognized cause of aortic aneurysms. Preoperative diagnosis is challenging, especially with the isolated form. High level of suspicious is required to investigate the patients with MRI or PET scan further. Patients with diagnosed autoimmune aortitis are prone to the development of the distal aortic 
disease, and endovascular intervention is feasible in those patients. Patients with concomitant aortic valve can be managed with the aortic valve-sparing procedure, and preoperative screening for coronary disease is recommended. Immunosuppressants should be used early before aortic dilatation, and its role postoperatively is controversial.

\section{Abbreviations}

CABG: Coronary artery bypass grafting; CT: Computed tomography; ESC: European Society of Cardiology; GCA: Giant cell arteritis; IgG4: Immunoglobulin G4; MRI: Magnetic resonance imaging; PET: Positron emission tomography; TEVAR: Thoracic endovascular aortic repair

\section{Acknowledgements}

None.

\section{Author's contributions}

AA did the literature search, wrote the manuscript, and approved the final version.

\section{Funding}

None.

\section{Availability of data and materials}

Non-applicable (this is a review article).

\section{Ethics approval and consent to participate}

Not applicable.

\section{Consent for publication}

Not applicable.

\section{Competing interests}

The author declares that he has no competing interests.

Received: 5 July 2019 Accepted: 16 September 2019

Published online: 20 November 2019

\section{References}

1. Svensson LG, Arafat A, Roselli EE, Idrees J, Clifford A, Tan C et al (2015) Inflammatory disease of the aorta: patterns and classification of giant cell aortitis, Takayasu arteritis, and nonsyndromic aortitis. J Thorac Cardiovasc Surg 149(2 Suppl):S170-S175

2. De Martino A, Ballestracci P, Faggioni L, Pratali S, Morganti R, Pucci A et al (2018) Incidence of aortitis in surgical specimens of the ascending aorta clinical implications at follow-up. Semin Thorac Cardiovasc Surg https:// www.ncbi.nlm.nih.gov/pubmed/30414447

3. Erbel R, Aboyans V, Boileau C, Bossone E, Bartolomeo RD, Eggebrecht H et al (2014) 2014 ESC Guidelines on the diagnosis and treatment of aortic diseases: document covering acute and chronic aortic diseases of the thoracic and abdominal aorta of the adult. The Task Force for the Diagnosis and Treatment of Aortic Diseases of the European Society of Cardiology (ESC). Eur Heart J 35(41):2873-2926

4. Arafat AA, Torky MA, Elhamshary M, Aboelnasr M (2019) Immunoglobulin G4 thymic tumor. Ann Thorac Surg 108(4):e229-e23. https://www.ncbi.nlm. nih.gov/pubmed/30914283

5. Jennette JC, Falk RJ, Bacon PA, Basu N, Cid MC, Ferrario F et al (2013) 2012 revised International Chapel Hill Consensus Conference Nomenclature of vasculitides. Arthritis Rheum 65(1):1-11

6. Jennette JC (2013) Overview of the 2012 revised International Chapel Hill Consensus Conference nomenclature of vasculitides. Clin Exp Nephrol 17(5): 603-606

7. Arend WP, Michel BA, Bloch DA, Hunder GG, Calabrese LH, Edworthy SM et al (1990) The American College of Rheumatology 1990 criteria for the classification of Takayasu arteritis. Arthritis Rheum 33(8):1129-1134

8. Hunder GG, Bloch DA, Michel BA, Stevens MB, Arend WP, Calabrese LH et al (1990) The American College of Rheumatology 1990 criteria for the classification of giant cell arteritis. Arthritis Rheum 33(8):1122-1128
9. Grayson PC, Maksimowicz-McKinnon K, Clark TM, Tomasson G, Cuthbertson D, Carette $S$ et al (2012) Distribution of arterial lesions in Takayasu's arteritis and giant cell arteritis. Ann Rheum Dis 71(8):1329-1334

10. Miller DV, Isotalo PA, Weyand CM, Edwards WD, Aubry MC, Tazelaar HD (2006) Surgical pathology of noninfectious ascending aortitis: a study of 45 cases with emphasis on an isolated variant. Am J Surg Pathol 30(9):1150-1158

11. Rojo-Leyva F, Ratliff NB, Cosgrove DM 3rd, Hoffman GS (2000) Study of 52 patients with idiopathic aortitis from a cohort of 1,204 surgical cases. Arthritis Rheum 43(4):901-907

12. Gravanis MB (2000) Giant cell arteritis and Takayasu aortitis: morphologic, pathogenetic and etiologic factors. Int J Cardiol 75(Suppl 1):S21-S33 discussion S5-6

13. Arafat A, Roselli E, Clifford A, Idrees J, Tan C, Svensson L et al (2013) Abstract 16022: is proximal aortic repair sufficient for autoimmune aortitis? Circulation 128(suppl_22):A16022-A

14. Pipitone N, Salvarani C (2011) Idiopathic aortitis: an underrecognized vasculitis. Arthritis Res Ther 13(4):119

15. Schmidt J, Sunesen K, Kornum JB, Duhaut P, Thomsen RW (2011) Predictors for pathologically confirmed aortitis after resection of the ascending aorta: a 12-year Danish nationwide population-based cross-sectional study. Arthritis Res Ther 13(3):R87

16. Kerr LD, Chang YJ, Spiera H, Fallon JT (2000) Occult active giant cell aortitis necessitating surgical repair. J Thorac Cardiovasc Surg 120(4):813-815

17. Lee A, Luk A, Phillips KR, Lim KD, David TE, Butany J (2011) Giant cell aortitis: a difficult diagnosis assessing risk for the development of aneurysms and dissections. Cardiovasc Pathol 20(4):247-253

18. Zehr KJ, Mathur A, Orszulak TA, Mullany CJ, Schaff HV (2005) Surgical treatment of ascending aortic aneurysms in patients with giant cell aortitis. Ann Thorac Surg 79(5):1512-1517

19. Gornik HL, Creager MA (2008) Aortitis. Circulation 117(23):3039-3051

20. Restrepo CS, Ocazionez D, Suri R, Vargas D (2011) Aortitis: imaging spectrum of the infectious and inflammatory conditions of the aorta. Radiographics 31(2):435-451

21. Bley TA, Ness T, Warnatz K, Frydrychowicz A, Uhl M, Hennig J et al (2007) Influence of corticosteroid treatment on MRI findings in giant cell arteritis. Clin Rheumatol 26(9):1541-1543

22. Tso E, Flamm SD, White RD, Schvartzman PR, Mascha E, Hoffman GS (2002) Takayasu arteritis: utility and limitations of magnetic resonance imaging in diagnosis and treatment. Arthritis Rheum 46(6):1634-1642

23. Blockmans D, Stroobants S, Maes A, Mortelmans L (2000) Positron emission tomography in giant cell arteritis and polymyalgia rheumatica: evidence for inflammation of the aortic arch. Am J Med 108(3):246-249

24. Rahman MS, Storrar N, Anderson LJ (2013) FDG-PET/CT in the diagnosis of aortitis in fever of unknown origin with severe aortic incompetence. Heart 99(6):435-436

25. Trad S, Bensimhon L, El Hajjam M, Chinet T, Wechsler B, Saadoun D (2013) 18F-fluorodeoxyglucose-positron emission tomography scanning is a useful tool for therapy evaluation of arterial aneurysm in Behcet's disease. Joint Bone Spine 80(4):420-423

26. Cozijnsen L, Ter Borg EJ, Braam RL, Seldenrijk CA, Heijmen RH, Bouma B et al (2019) Ascending aortic aneurysm secondary to isolated noninfectious ascending aortitis. J Clin Rheumatol 25(4):186-194

27. Nuenninghoff DM, Hunder GG, Christianson TJ, McClelland RL, Matteson EL (2003) Mortality of large-artery complication (aortic aneurysm, aortic dissection, and/or large-artery stenosis) in patients with giant cell arteritis: a population-based study over 50 years. Arthritis Rheum 48(12):3532-3537

28. Hiratzka LF, Bakris GL, Beckman JA, Bersin RM, Carr VF, Casey DE Jr et al (2010) 2010 ACCF/AHA/AATS/ACR/ASA/SCA/SCAI/SIR/STS/SVM guidelines for the diagnosis and management of patients with thoracic aortic disease: executive summary. A report of the American College of Cardiology Foundation/American Heart Association Task Force on Practice Guidelines, American Association for Thoracic Surgery, American College of Radiology, American Stroke Association, Society of Cardiovascular Anesthesiologists, Society for Cardiovascular Angiography and Interventions, Society of Interventional Radiology, Society of Thoracic Surgeons, and Society for Vascular Medicine. Catheter Cardiovasc Interv 76(2):E43-E86

29. Clifford AH, Arafat A, Idrees JJ, Roselli EE, Tan CD, Rene Rodriguez E, Svensson LG, Blackstone E, Johnston D, Pettersson G, Soltesz E, Hoffman GS (2019) Outcomes among 196 patients with non-infectious proximal aortitis. Arthritis Rheumatol (Hoboken, NJ) https://doi.org/10.1002/art 40855. https://www.ncbi.nlm.nih.gov/pubmed/30730604 
30. Wang H, Smith RN, Spooner AE, Isselbacher EM, Cambria RP, MacGillivray TE et al (2012) Giant cell aortitis of the ascending aorta without signs or symptoms of systemic vasculitis is associated with elevated risk of distal aortic events. Arthritis Rheum 64(1):317-319

31. Gagne-Loranger M, Dumont E, Voisine P, Mohammadi S, Garceau C, Dion B et al (2016) Giant cell aortitis: clinical presentation and outcomes in 40 patients consecutively operated on. Eur J Cardio-thoracic Surg 50(3):555559

32. Cinar I, Wang H, Stone JR (2017) Clinically isolated aortitis: pitfalls, progress, and possibilities. Cardiovasc Pathol 29:23-32

33. Baril DT, Carroccio A, Palchik E, Ellozy SH, Jacobs TS, Teodorescu V et al (2006) Endovascular treatment of complicated aortic aneurysms in patients with underlying arteriopathies. Ann Vasc Surg 20(4):464-471

34. Preventza O, Mohammed S, Cheong BY, Gonzalez L, Ouzounian M, Livesay $J J$ et al (2014) Endovascular therapy in patients with genetically triggered thoracic aortic disease: applications and short- and mid-term outcomes. Eur JCardio-thorac Surg 46(2):248-253 discussion 53

35. Ogino H (2019) Surgical strategy for refractory aortitis. Gen Thorac Cardiovasc Surg 67(1):25-31

36. Gaudric J, Dennery M, Jouhannet C, Kagan N, Saadoun D, Chiche L et al (2016) Aortitis and surgery. La Revue de Medecine Interne 37(4):284-291

37. Arworn S, Orrapin S, Chakrabandhu B, Reanpang T, Settakorn J, Laohapensang K (2018) Aorto-enteric fistula after endovascular abdominal aortic aneurysm repair for Behcet's disease patient: a case report. EJVES Short Rep 39:54-57

38. Imai S, Tahara N, Hiromatsu S, Fukumoto Y, Tanaka H (2018) Endovascular repair for inflammatory abdominal aortic aneurysm. Eur Heart J Cardiovasc Imaging 19(10):1191-1192

39. Duque Santos A, Reyes Valdivia A, Romero Lozano MA, Aracil Sanus E, Ocana Guaita J, Gandarias C (2018) Outcomes of open and endovascular repair of inflammatory abdominal aortic aneurysms. Vascular 26(2):203-208

40. Arafat A, Roselli EE, Idrees JJ, Feng K, Banaszak L, Eagleton M et al (2016) Stent grafting acute aortic dissection: comparison of DeBakey extent IIIA versus IIIB. Ann Thorac Surg 102(5):1473-1481

41. Jansen M, Saleh S, Bolster M, O'Donnell A, Ahern T, Spence L et al (2010) Thoracic vasculitis presenting as surgical problems. Virchows Archiv 456(1):91-96

42. Mennander AA, Miller DV, Liang KP, Warrington KJ, Connolly HM, Schaff HV et al (2008) Surgical management of ascending aortic aneurysm due to non-infectious aortitis. Scand Cardiovasc J 42(6):417-424

43. Nishimura S, Amano M, Izumi C, Kuroda M, Yoshikawa Y, Takahashi Y et al (2016) Multiple coronary artery aneurysms and thoracic aortitis associated with lgG4-related disease. Internal medicine (Tokyo, Japan) 55(12):1605-1609

44. Zambetti BR, Garrett E Jr (2016) Plasmacytic aortitis with occlusion of the right coronary artery. Am J Case Rep 17:549-552

45. Tran MN, Langguth D, Hart G, Heiner M, Rafter A, Fleming SJ et al (2015) lgG4-related systemic disease with coronary arteritis and aortitis, causing recurring critical coronary ischemia. Int J Cardiol 201:33-34

46. Oyama-Manabe N, Yabusaki S, Manabe O, Kato F, Kanno-Okada H, Kudo K (2018) IgG4-related cardiovascular disease from the aorta to the coronary arteries: multidetector CT and PET/CT. Radiographics 38(7):1934-1948

47. Blumstein H, Kerr LD, Fallon JT (2006) Giant cell aortitis with histopathologic and clinical response to steroid therapy: a case report. J Thorac Cardiovasc Surg 132(6):1467-1468

\section{Publisher's Note}

Springer Nature remains neutral with regard to jurisdictional claims in published maps and institutional affiliations.

\section{Submit your manuscript to a SpringerOpen ${ }^{\circ}$ journal and benefit from:}

- Convenient online submission

- Rigorous peer review

- Open access: articles freely available online

- High visibility within the field

- Retaining the copyright to your article

Submit your next manuscript at $\boldsymbol{\nabla}$ springeropen.com 